\title{
KOSGEB Desteklerinin Destekleri Kullanan İşletmeler Açısından Değerlendirilmesi (TR33 Bölgesi Uygulaması)
}

\author{
Tuğrul KANDEMİ ${ }^{*}$, Ender BAYKUT ${ }^{* *}$, Abdullah AVCI ${ }^{* * *}$
}

ÖZ

Küçük ve Orta Ölçekli İşletmeleri Geliştirme ve Destekleme İdaresi Başkanlığı (KOSGEB) Desteklerinin, destekleri kullanan işletmeler açısından değerlendirilmesi (TR33 Bölgesi Uygulaması) konulu bu çalışmada öncelikle KOBİ Kavramı ve KOBİ'lerin yapısal analizi ele alınmış, KOBİ'lerin ekonomik önemi ve karşılaştıkları sorunlarla ilgili bilgilere yer verilmiștir. Daha sonra KOBİ'lerin desteklenmesinin önemi ve Türkiye'de KOBI'lere sağlanan destekler incelenmis ve KOSGEB tarafından KOBI'lere sunulan destek programları belirtilmiştir. TR33 Bölgesi'nin temel göstergeleri ele alındığ araştırma kısmında TR33 bölgesi illeri olan Afyonkarahisar, Kütahya, Manisa ve Uşak'ta 2010-2013 yılları arasında KOSGEB desteklerini kullanan işletmelerden oluşan 237 işletmelik örneklem grubuna anket yapılmak suretiyle bu işletmelerin KOSGEB destekleri hakkındaki genel değerlendirmeleri tespit edilmiştir. Çalışma sonuçlarına göre; genel olarak TR33 bölgesinde destek alan işletmelerin desteklerden, destek süreçlerinden ve KOSGEB'ten memnuniyet düzeyinin istatistikî olarak ortalamanın üzerinde olduğu görülmüștür. Çalışma kapsamında incelenen TÜiK ve KOSGEB verilerine göre TR33 Bölgesinin ekonomik göstergelerinin Türkiye'nin ekonomik göstergeleri ile benzer özellikler gösterdiği görülmektedir. Bu durum yapılan çalışmanın ülke geneli için bir bakış açısı oluşturabilmesi açısından önemlidir.

Anahtar Kelimeler: KOBİ, KOSGEB, Devlet Teşvikleri, TR33 Bölgesi

JEL Sinıflandırması: G21, G28, H25

\section{An Assessment of Small and Medium Enterprises Development Organization (KOSGEB) Incentives from the Perspective of Support Receiving Organizations (TR33 Region Implementation)}

\begin{abstract}
The aim of this study is to analyze Small and Medium Enterprises Development Organization Administration incentives and supports from the perspective of support receiving enterprises (TR33 Region Implementation). Firstly, concepts and structures of SME's, have been explained respectively. Then, elaborate on economic importance of SMEs and their problems have been investigated. The study has been also mentioned about importance of supporting SMEs, analyze the supports provided to SMEs in Turkey and underline the supports and incentives provided to SMEs by KOSGEB. In the research section, the main economic indicators of TR33 Region have been surveyed a sample of 237 companies, which already used KOSGEB supports and incentives between 2010-2013 in Afyonkarahisar, Kütahya, Manisa and Uşak. According to the study results, it was observed that, satisfaction level of support receiving companies in TR33 region is statistically higher than average for the KOSGEB supports and support processes in general. According to TÜIK and KOSGEB data that we analyzed, economic indicators of TR33 Region are similar to those of Turkey. This outcome is significant and it shows that our study provides a perspective for the understanding of general nationwide perception.
\end{abstract}

Keywords: SME, KOSGEB, Government Incentives, TR33 Region

JEL Classification: G21, G28, H25

Geliş Tarihi / Received: 01.11.2016 Kabul Tarihi / Accepted: 13.12.2016

\footnotetext{
* Doç. Dr., Afyon Kocatepe Üniversitesi, İşletme Bölümü, kandemir@aku.edu.tr

** Arş. Gör., Afyon Kocatepe Üniversitesi, İngilizce İşletme Bölümü, ebaykut@aku.edu.tr

*** Uzman, KOSGEB.
} 


\section{GİRIŞ}

Türkiye ekonomisinin önemli bir bölümünü kapsayan ve ekonominin bel kemiği konumunda olan KOBI'ler, günümüz yaşantısında değişim ve rekabete kolay uyum sağlayabilen yapılar olarak karşımıza çıkmaktadırlar. Ekonomik büyüklükleri ve yapılarındaki farklılaşmalara rağmen özellikle istihdam ve üretim açısında ülkeler için sundukları olanaklar hem gelişmiş hem gelişmekte olan hem de az gelişmiş ülkeler için büyük önem taşımaktadır. Bu açıdan KOBİ'ler, ülke ekonomilerinde son derece önemli bir yere sahip olmaları nedeniyle ekonomik canlılığın da önemli bir göstergesi durumundadırlar. KOBİ'lerin bu niteliği özellikle kriz dönemlerinde kendisini göstermekte ve görece olarak gelişmekte olan ile az gelişmiş ülkelerde etkisini daha yaygın şekilde hissettirmektedir. Dolayısıyla KOBİ'ler ülkelerin krizden çıkış hızlarını ve ekonomik gelişmelerini arttırıcı bir etki yaratmaktadır. Bu durumun temel nedeni ise KOBİ'lerin küçük olma avantajını kullanarak süreçlere ve olaylara daha kolay uyum sağlayabilmesine olanak veren esnek yapılarından kaynaklanmaktadır. Değişime ve rekabete kolay uyum sağlayamayan, esnekliği olmayan KOBİ'ler ise günden güne artan sorunlar ve problemlerle karşılaşmakta, bu durumun nihai sonucunda ise büyük ölçekli işletmeler tarafından piyasa dışına atılmaktadırlar.

Tüm dünyada olduğu gibi ülkemiz için de hayati derece öneme sahip olan KOBI'lerin rekabet gücünün ve esnekliğinin arttırılması, devletlerin ve devlet kurumlarının asli hedeflerinden biridir. Bireylerin ve işletmelerin ihtiyaçlarının karşılanmasında KOBİ payının arttırılması amacıyla kurulan KOBİ'ler, KOSGEB tarafından verilen çeşitli yardımlar ile desteklenmektedir. KOBI'lerin rekabet gücünün ve esnekliğinin arttırılmasını da amaç edinen KOSGEB, KOBI'lerin gerek finansal gerekse yönetsel gününün arttırılması ile beraber sanayi entegrasyonun sağlanmasına da öncülük etmektedir. Bu çalışma temel olarak KOSGEB desteklerinden faydalanan işletmelerin bakış açılarını değerlendirmek üzere yapılmışıtır. Çalışma kapsamında TR33 Bölgesi illeri olan Afyonkarahisar, Kütahya, Manisa ve Uşak' ta 2010-2013 yılları arasında KOSGEB desteklerinden faydalanan 2158 işletmeden 237'si ile anket yöntemi kullanılarak alan araştırması yapılmıştır. Araştırma verileri, söz konusu işletmelerin yönetici, sahip veya ortaklarına yönelik olarak hazırlanan ve elektronik posta adreslerine gönderilen anket formu aracılığıyla toplanmıştır. Elde edilen veriler çeşitli analizlere tabi tutularak sonuca ulaşılmaya çalışılmış ve çalışmanın literatürde bu konu ile ilgili oluşan açığg kapatması amaçlanmıştır.

Çalışmanın ikinci bölümünde KOBİ kavramı ele alınmış olup daha sonrasında ise KOBİ'ler ile ilgili literatür taramasına yer verilmiştir. Üçüncü bölümünde veri seti ve uygulanacak yöntemler anlatıldıktan sonra dördüncü bölümde analizler yapılmış ve çalışma sonuç-değerlendirme bölümü ile tamamlanmıştır.

\section{KOBİ KAVRAMI}

KOBİ (Küçük ve Orta Büyüklükteki İşletme) kavramı, genel olarak bütün ülkelerde kullanılan bir kavram olmasına rağmen, literatürde KOBİ'ler üzerine çalışma yapan araştırmacılarca kabul görmüş, spesifik bir KOBİ tanımı bulunmamaktadır (Durman ve Önder, 2007). Bunun temel nedeni ise kavramın ülke, bölge, kültür ve yöreye göre farklılaşmasından kaynaklanmaktadır (Olcay, 1996).

Literatürde de görüleceği üzere hemen hemen her ülkenin kendisine ait bir KOBİ tanımı bulunmaktadır. Bu durumun genel nedeni, ülkelerin temel olarak KOBİ'lerin etkinlik, verimlilik ve rekabet avantajlarını arttırmak üzere uygulamayı planladıkları politika farklılıklarıdır. Ülkelerin belirlemiş oldukları bu politikalar ve program hedefleri değiştikçe buna bağlı olarak KOBİ tanımı da değişmektedir (Cansız, 2008). Bu çerçevede, ülkenin ekonomi politikaları ve 
kaynakları esas alınmak üzere, satış hacmi, bilanço büyüklüğü, çalışan sayısı ve yatırılan sermaye tutarı gibi kriterlerden bir ya da birkaçı kullanılarak KOBİ tanımı yapılmaktadır.

Türkiye'de ise KOBİ'ler üzerine çalışan birden fazla kurum olduğundan her kurum kendisine ait bir KOBİ tanımı yapmıştır. Fakat bu tanımların hemen hemen hepsi, KOBİ'lerin farklı boyutlarına değindiğinden genel bir KOBİ tanımı ortaya çıkmamış ve genel kabul görmüş bir tanımın gereksinimini ortaya çıkarmıştır. Ayrıca Avrupa Birliği ile ilgili süreçlerde ve işbirliklerinde genel bir tanımın olmayışından kaynaklı ortaya çıkan sorunların çözümü için Bakanlar Kurulu tarafindan alınan karar ve 18 Kasım 2005 tarihinde Resmi Gazetede yayımlanan yönetmelik ile genel bir KOBİ tanımı artık kullanılmaya başlanmıştır.

2005 yılında yapılan tanımın ardından yapılan güncelleme çalışmaları ile KOBİ kavramı 2012 yılında tekrar tanımlanmıştır. Gümrük ve Ticaret Bakanlığı, Bilim, Sanayi ve Teknoloji Bakanlığı, AB Bakanlığı, KOSGEB, Kamu Gözetimi, Muhasebe ve Denetim Standartları Kurumu, TÜIK, TESK ve TOBB'un katılımıyla gerçekleştirilen çalışmalar sonucunda yeni bir KOBİ tanımı yapılmıştır. Bu tanım ise, 4 Kasım 2012 tarihinde Resmi Gazete'de yayımlanmış ve yayım tarihinde yürürlüğe girmiştir. Ülkemizde hâlihazırda geçerli olan KOBİ tanımı, nitelikleri ve sınıflandırılması bu yönetmelikle düzenlenmiştir. Bu başlık altında verilen bilgiler bu yönetmelikten alıntılanmıştır. Bu tanıma göre;

"Kü̧̈ük ve Orta Büyüklükte İşletme (KOBİ): İki yüz elli kişiden az ylllık çalışan istihdam eden ve yıllık net satı̧̧ hâsılatı veya mali bilanço değerinden herhangi biri kırk milyon Türk Lirasını aşmayan ve mikro işletme, küçük işletme ve orta büyüklükteki işletme olarak sinfflandırllan ekonomik birimleri veya girişimleri ifade etmektedir. "

KOBİ'lerin en önemli özellikleri büyük olmamalarıdır. KOBİ'ler genellikle bulundukları sektör veya pazarda ilk \%10 veya \%20'lik bölüme girmezler. Buna karşın KOBİ'ler büyük işletmelere nazaran birçok avantaja sahiptirler. Bu avantajlardan en önemlisi işletmelerin sahip oldukları yöneticiler ve dinamik yapıdır. Günümüzde faaliyetlerine devam eden büyük ölçekli işletmelerin birçoğu dinamik lider tipleriyle iyi yönetilmesi sonucunda önceden birer KOBİ iken artık büyük bir işletme haline gelmişlerdir (Erol, 2010). KOBİ'lerin sahip oldukları dinamiklik OECD (2002) raporuna göre ayrıca piyasaya giriş ve çıkışta da kendisini göstermektedir. Piyasaya giriş ve çıkışları, büyük işletmelere nazaran daha kolay olan KOBİ'ler ölçeğe göre getiri bakımından da büyük işletmelerden daha fazla büyümektedirler. Iraz 'a (2005) göre, KOBİ'lerin ekonomi için bir lokomotif işlevi gördüğünün birçok kanıtı vardır. Bunlar; istihdamı arttırması, bireylerin refah düzeyinin artması, teknolojik gelişme, gelir dağılımının düzelmesi ve modernleşmedir. ILO'ya (2005) göre ise bu faktörler ulusal ekonomiler için olduğu kadar küresel ekonominin de büyümesi için önemlidir.

KOBİ'lerin küçük olmaları sebebiyle sahip oldukları avantajlar kadar dezavantajları da mevcuttur. Bu dezavantajlardan kaynaklanan sıkıntılar ise bazen KOBI'lerin kapanmasına, büyümesinin engellenmesine veya büyük ölçekli işletmeler tarafından yok edilmelerine neden olmaktadır. Özdemir vd. (2006) göre bu olumsuz faktörler şu şekilde sıralanabilir; finansmana ulaşım ve zayıf sermaye yapısı, pazar sorunu, teknolojik gelişmeleri takip edememe veya uyum sağlayamama, yönetsel yetersizlikleri, yüksek oranlı vergiler ve prim maliyetlerinin yüksekliği, ihracat yapmadaki zorluklar, nitelikli işgücü eksikliği, piyasalara girişte karşılaşılan zorluklar ve dönemsel satış farklılıklarıdır.

KOBI'lerin büyük işletmeler karşısındaki bu dezavantajları ve karşılaştıkları sorunlar bazen kendi başlarına çözemeyecekleri boyutlara ulaşmaktadır. Bu noktada devletlere düşen görev ise KOBI'lerin desteklenmesi ve sorunlarının çözüm yollarının aranmasıdır. Ortaya çıkacak olan bu sonuçlar ile ekonominin canlılığı sürdürülebilir kılınıp ayrıca ortaya çıkabilecek olan mikro ölçekli krizlere engel olunabilecektir (Özdemir vd., 2006). Günümüzde ise artık KOBİ politikaları yerel olmaktan çıkıp uluslararası nitelik kazanmıştır. Ülkelerin ekonomi durumlarına bağlı olmaksızın gelişmiş veya az gelişmiş ülkelerde yaygınca olmak üzere, kendi 
ülkelerinin KOBİ'lerini koruma amaçlı bazı politikalar izlemektedirler. Bu politikaların genel amacı ise çoğunlukla pazar payını koruma ve arttırmaya yöneliktir. $\mathrm{Bu}$ amacı yerine getirmek için ise; KOBİ'lere verilen destekler üzerinde uluslararası düzeyde sınırlayıcı ve belirleyici tedbirler alarak KOBİ'lerin gerek iç gerekse dış pazarlarda rekabet düzeylerini arttırma ve uygun iş ortamı oluşturmaya yönelik kararları yürürlüğe koymuşladır (Cansız, 2008). KOBİ'lerin desteklenmesi, geliştirilmesi ve rekabet avantajının arttırılmasına yönelik çalışmalara bakıldığında ise bu çalışmaların büyük bölümünün kamu tarafından yapıldığı görülmektedir. Bu çalışmaların önemli bir bölümünde ise KOBİ’lerin teknoloji talebini nasıl karşılayacakları, finansmana ulaşım yolları ile eğitim ve danışmanlık konularını kapsadığı tespit edilmiştir (Valandova, 2003).

Ülkemizde ise KOBİ'lerin sorunlarına çözüm olabilmek ve devlet desteklerinin KOBI'lere ulaştırılması konusunda aracı olup onların gelişmesine olanak sağlamak amacıyla KOSGEB (Küçük ve Orta Ölçekli İşletmeleri Geliştirme ve Destekleme İdaresi Başkanlığı) kurulmuştur. 5 Mayıs 2009 tarihinde Resmi Gazete'de yayınlanarak kurulan bu kurum, ülkemizde KOBI'lerden sorumlu ulusal kuruluş niteliğine kavuşmuştur (KOSGEB, 2011).

KOSGEB çok çeşitli başlıklar altında hâlihazırda KOBİ'lere birçok destek hizmeti vermektedir. $\mathrm{Bu}$ destek hizmetlerinden bazıları ise şu şekilde sıralanabilir; Gelişen İşletmeler Piyasası ve Kredi Faiz Desteği Programı, KOBİ Proje Destek Programı, Tematik Proje Destek Programı, İşbirliği-Güçbirliği Proje Destek Programı, AR-GE, İnovasyon ve Endüstriyel Uygulama Destek Programı, Girişimcilik Destek Programı, KOBİ Destek Programı ve Genel Destek Programı'dır (KOSGEB, 2016).

Çalışmanın izleyen bölümünde KOBI'ler ile ilgili literatür taramasına yer verilmiştir. Daha sonrasında ise çalışmanın veri ve metodolojisi kısmı anlatılacak olup, analiz bölümüne geçilecektir.

\section{LITERATÜR TARAMASI}

KOSGEB desteklerinin KOBİ'ler üzerindeki etkilerini farklı açılardan ele alan çalışmalar incelendiğinde, genel olarak çalışmaların büyük oranda benzer sonuçlara ulaştı̆̆ı tespit edilmiştir. Elde edilen bu sonuçlara göre; KOSGEB desteklerinin daha etkin duyurulması ve bürokratik işlemlerin azaltılması yoluyla, desteklerin daha yüksek sayıda KOBİ tarafindan kullanılacağı ve etkinlik/verimliliğinin de artacağı belirlenmiştir. İlgili literatür taraması özet olarak bu bölümde ele alınmıştır. Ayrıca literatür taraması sonucunda elde edilen sonuçlara göre, daha önceden KOSGEB desteklerini alan işletmeler üzerine, desteklerin değerlendirilmesine ilişkin bir çalışmaya rastlanmamıştır. Dolayısıyla mevcut çalışma literatürdeki bu eksiği gidermeyi amaçlamaktadır.

Aycı tarafından 2011 yılında yapılan çalışmada, 2006 yılı itibariyle KOSGEB tarafından yurtdışı fuarlara katılım desteği sağlanan 101 KOBİ araştırma kapsamında değerlendirilmiştir. Yurtdış1 desteğini kullanan toplam 91 işletmenin sahip veya yöneticisine uygulanan anket kapsamında, katılımcılara yurtdışı fuarlara katılım amaçları ve bu amaca ulaşıp ulaşamadıkları sorulmuştur. Yurtdışı fuarlara destekli veya desteksiz her koşul altında katılacağını beyan eden işletmeler ile sadece destek aldıkları zaman katılabileceklerini beyan eden işletmelerin başarı durumları karşıllaştırıldığında; sadece destek aldığı zaman yurtdışı fuarlara katılacağını beyan eden işletmeler her koşulda fuarlara katılacağını beyan eden işletmelerden daha başarılı oldukları tespit edilmiştir. Araştırma sonucunda tespit edilen bir diğer husus ise; işletmelerin yurtdış1 fuarlara katılım ve destekleri konusunda bilgilendirilmesi ile daha çok işletmenin bu destekten yararlanabileceğidir. 
Ankara'da faaliyet gösteren mobilya sanayicilerinin yaşamakta olduğu finansal sorunlar ve bu sorunların çözüm önerilerinin ele alındığı Sarıkahya tarafından 2012 yılında yapılan çalışmada ise KOBI'lerin devlet desteklerinden yararlanma durumları tespit edilmeye çalışılmıştır. Tesadüfi örneklem yoluyla belirlenen işletmeler üzerinden elde edilen verilere göre yapılan çalışma sonucunda, işletmelerin KOSGEB ve devlet desteklerinden çok fazla yararlanamadıkları bunun nedeninin ise bilgilendirme eksikliği ve duyuruların yetersiz olduğu tespit edilmiştir. KOBİ'lerin devlet ve KOSGEB desteklerinden az oranda yararlanmasının nedeni literatürde de yer aldığı üzere, desteklere ulaşırken karşılaşılan bürokratik engeller, duyuruların az ve yetersiz/etkisiz oluşu, bilgilendirmenin az olması ile ilgilidir. Fakat özellikle iller bazında, bir ildeki KOSGEB biriminin etkili ve yaygın duyuru yapması, bilgilendirmeye önem vermesi ve desteklerin ildeki billboardlardan duyurulması bu sonucu tersine çevirmekte ve hem desteklerin miktarının hem de desteklerin etkinliğinin artmasına olanak sağlamaktadır. Bu durumun göstergesi nitelindeki çalışma 2013 yılında Yıldız tarafından yapılmıştır. KOBİ'lere sağlanan devlet desteklerinin etki değerlemesini ele alan yazar, kullanılan desteklerin hedefine ulaşıp ulaşmadığını tespit etmeye çalışmıştır. Yazarın çalışmasının sonucunda elde ettiği bilgilere göre; KOBİ'lerin destekleri kullanım aşamasında daha az bürokratik işlemlere maruz kalması, destekleri kullanan şirket sayısında ciddi bir artış olduğunu göstermiştir. Bu artış aynı zamanda kullanılan destek miktarının da artmasını sağlamıştır. Yazara göre, bu artışın sürekli ve sürdürülebilir olması için öncelikle hedef grubun doğru tanımlanması daha sonrasında ise ihtiyaç analizlerinin iyi yapılması gerekmektedir. Destek programlarının uygun araçlar ile oluşturulması, düzenli bir şekilde uygulamanın izlenmesi, uygulama esnasında ortaya çıkacak sorunlar için tedbir alınması ve gelişmelerin değerlendirilmesi yazarın çalışmasının sonucunda öneri olarak ortaya koyduğu saptamalardır. KOBİ'lerin KOSGEB desteklerinden yararlanma düzeylerini ve yaşadıkları sorunları ele alan bir diğer çalışma ise Ar tarafından 2009 yılında yapılmıştır. Konya'da bulunan KOBİ'ler üzerine yapılan çalışmadan elde edilen sonuçlara göre; daha çok işletmenin KOSGEB desteklerinden yararlanması için; bölgesel ve sektörel olmak üzere ihtiyaçların doğru tespit edilmesi, desteklerin denetlenmesi ve uzman kişilerin süreç içerisinde yer almasi gerekmektedir.

KOSGEB tarafından verilen Girişimcilik Kursuna katılan kursiyerler üzerine Mutlu (2014) tarafından yapılan çalışmada ise, kursiyerlerin girişimci olma istekleri ve bu isteğin ardında yatan nedenler ile girişimciliğe bakış açıları ele alınmıştır. Ayrıca kursiyerler için girişimciliğe engel olan unsurların neler olduğu tespit edilmeye çalış1lmıştır. Toplam 117 girişimcinin katıldığı çalışmanın sonuçlarına göre; kursiyerlerin girişimcilik kursuna katılıp sertifika almasının en önemli sebebi, bir başkasından bir şeyler beklemektense kendisi için bir şey yapması gerektiğine inanmasıdır. Yine çalışmadan ortaya çıkan bir diğer sonuç ise girişimciliğin önündeki en büyük engelin sermaye olduğudur. Ayrıca kursiyerler katıldıkları kurs ve alacakları sertifika ile ilgili olumlu görüş belirtirken bu süreçte KOSGEB'in görevini yerine getirdiğini söylemleri ise çalışmadan elde edilen bir diğer sonuçtur.

KOBI'leri destekleyen kurum ve kuruluşların işlemlerinde bürokratik işlemleri azaltmalar hem desteklerin artmasına hem de destek kabul işlemlerinin hızlanmasına olanak sağlamaktadır. Öktem vd. (2007) tarafından yapılan çalışmada ise 3 farklı gruptan oluşan 92 kişinin dâhil olduğu bir çalışma yapılmıştır. Çalışmaya katılan birinci grup OSTİM'de yer alan KOBI'lerin sahipleridir. Diğer gruplar ise KOSGEB'in Girişimcilik Kursuna katılan kursiyerler ve son olarak ODTÜ-KOSGEB TEKMER'deki kuluçka merkezinde yer alan işletme sahipleridir. Bu 3 gruptaki kişilere, kamu desteklerinden yararlanılırken yaşadıkları sorunlar ve girişimciliğin geliştirilmesi için neler yapılması gerektiği sorulmuştur. Çalışmanın sonucuna göre; KOSGEB'in faaliyetlerinin daha da hızlandırılmas1 ve eksiklerinin giderilmesi halinde Türkiye'de girişimciliğin geliştirilmesinde etkisinin daha da yükseltilebileceği kanaatine varılmıştır. Göller Bölgesi'nde faaliyette bulunan KOBİ'lerin KOSGEB desteklerinden yararlanma durumlarını inceleyen Maden ve Dulupçu ise 2014 yılında yaptıkları çalışmada, 
Logit ve Tobit modelleri ile desteklerden yararlanan ve yararlanmayan işletmelerin performanslarını ölçmüştür. Desteklerinden yararlanan işletmelerin deney grubu, desteklerden yararlanmayan işletmelerin ise kontrol grubu olarak tanımlandığı çalışmada, KOBI'lerin performansları değişik kriterler esas alınarak karşılaştırılmıştır. Toplam 294 KOBİ üzerine yapılan çalışmada, kamu desteklerinden faydalanan işletmelerin; istihdam, üretim ve müşteri sayısı bakımından bu desteklerden faydalanmayan işletmelere nazaran istatiksel olarak anlamlı farklılıklar yarattığı ortaya çıkmıştır.

Uşak Üniversitesi İİB öğrencilerinin, KOSGEB Girişimcilik Destek Programı kapsamında aldıkları eğitimin sonuçlarını analiz eden Akyüz (2013) ise öğrencilerin girişimcilik özellikleri ve girişimcilik eğilimlerini anket yöntemiyle incelediği çalışmasında, öğrencilerin önemli bir bölümünün KOSGEB eğitimleri ile ilgili olumlu görüş bildirdikleri ortaya çıkmıştır. Çalışmaya katılan öğrencilerin büyük bölümünün $(\% 56,9)$ mezun olduktan sonra memur olmak istediğini belirten yazar, bu durumun nedeni olarak üniversitede verilen girişimcilik dersinin sadece teorik olarak derslerle sınırlı kaldığını ve uygulama aşamasının da olması gerektiğini belirttiği görülmüsştür. Yazarın tespit ettiği bir diğer husus ise, Türk öğrencilerin yabancı ülke öğrencilerine nazaran daha düşük oranda girişimcilik ruhuna sahip olmasının nedeni; kültür farklılığı ve eğitim yönünden ortaya çıkan eksikliktir. Bu sonuca rağmen, çalışmaya katılan öğrencilerin \%64,2'si "KOSGEB hizmetlerinden yararlanmak istiyorum" önermesine olumlu yanıt vererek bir yönüyle girişimcilik konusunda istekli olduklarını belirtmişlerdir. Ayrıca çalışmaya katılım gösteren öğrencilerin \%71'lik kısmı KOSGEB hizmetlerine internetten ulaşabildiklerini belirtmişlerdir.

\section{METODOLOJİ}

$\mathrm{Bu}$ çalışmada, uygulamalı araştırma modellerinden biri olan 'anket' yöntemi kullanılmıştır. Anket ile elde edilen verilerin gerçekçi olması açısından anket formu, işletme sahibi ya da yönetim kademesinde yer alan kişilerin e-posta adreslerine gönderilmiştir. Yapılan anket çalışması iki kısımdan oluşmaktadır. İlk kısımda KOSGEB desteklerinden faydalanan işletmelerin hukuki statüsü, personel sayısı, faaliyet alanı, fiziki konumu gibi temel işletme bilgilerine ulaşılmaya çalışılmıştır. Bu kısımda yer alan sorular literatür taraması sonucunda oluşturulmuş, ayrıca literatürde daha önce yer almayan ve gözlemler sonucu ortaya çıkan önermeler ise literatürde oluşan bu açığı doldurmak üzere hazırlanmıştır. Anketin ikinci kısmında ise daha önce KOSGEB desteklerinden yararlanan işletmelerin KOSGEB destekleri hakkındaki görüş ve değerlendirmeleri belirlenmeye çalışılmıştır. Ankette yer alan soruların büyük bölümü, yalnız bir yanıtın olduğu önermelerdir. Bunun yanında katılımcıların birden fazla seçeneği aynı ayda işaretleyebileceği sorular da çalışmada kullanılmıştır.

Araştırma için gerekli olan verilerin toplanması Google Drive programı aracılığıyla ile internet üzerinden yapılmıştır. Anket sonucu elde edilen veriler istatistiksel paket programı kullanılarak analiz edilmiştir. Araştırma, KOSGEB desteklerinden faydalanan işletmelerin yapısal kriterleri, kullandıkları destek türleri ve belirlenen performans kriterleri çerçevesinde oluşturulan ve Tablo 1'de verilen model çerçevesinde yapılmıştır. 
Tablo 1: Model Çerçevesi

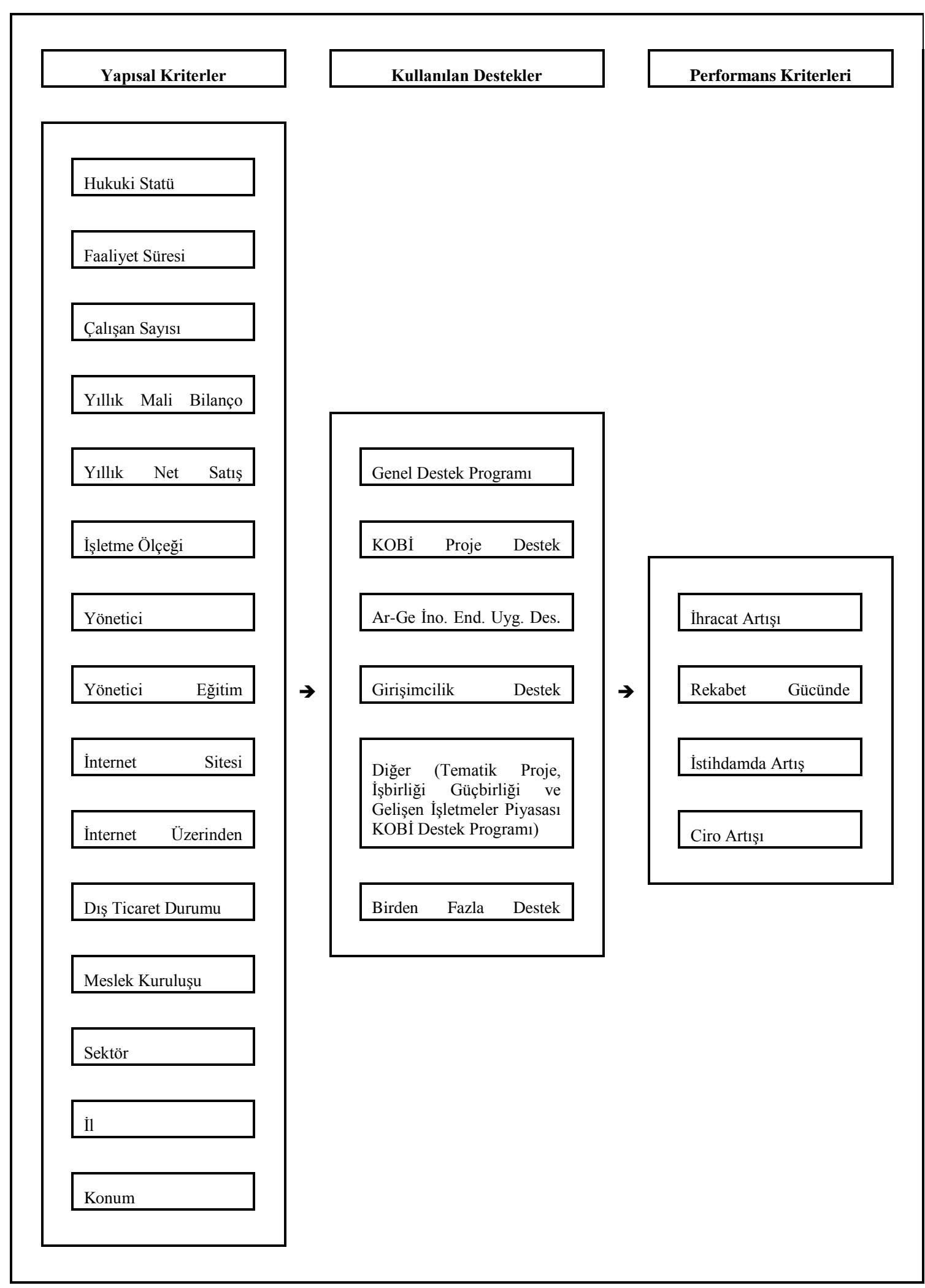


Optimum Journal of Economics and Management Sciences, Vo1. 4, No. 1- http://dergipark.ulakbim.gov.tr/usakoeyb/ Kandemir, Baykut and Avcl-An Assessment of Small and Medium Enterprises Development Organization (KOSGEB) Incentives from the Perspective of Support Receiving Organizations (TR33 Region Implementation)

\section{ANALIZ}

$\mathrm{Bu}$ bölümde, TR33 Bölgesinde faaliyet gösteren KOBİ'ler arasında KOSGEB desteklerinden faydalanan işletmelerin KOSGEB destekleri hakkında bilgi sahibi olmasından destek kullanım sürecine kadar geçirdiği aşamalar ve desteklerin etkinliği hakkındaki görüşlerini ölçmek amacıyla yapılan araştırma sonuçlarına yer verilmiştir. TR33 Bölgesinde bulunan ve KOSGEB desteklerinden faydalanan işletmeler arasından belirlenen bir örneklem kümesi üzerinden çalışılmıştır. Araştırma kapsamında elde edilen verilerin gerçeğe en yakın sonuçları yansıtabilmesi açısından, TR33 Bölgesinde faaliyet gösteren ve 2010 ile 2013 yılları arasında KOSGEB desteklerinden en az 1 defa faydalanmış olan 2158 işletmeye 20 Ocak 2014 tarihinde elektronik ortamdan anket formu gönderilmiştir. 2158 işletmeden 237 tanesi bu ankete 20 Ocak 2014-14 Şubat 2014 tarihleri arasında cevap vermiştir. 237 işletme üzerinden yapılan bu değerlendirme \%95 güven aralığında $\pm 0,05$ sapma ile doğru sonuçlar vermektedir.

TR33 Bölgesi'nde KOSGEB desteklerinden faydalanan işletme sayıları ile araştırmaya katılan işletme sayıları Tablo 2'de verilmiştir. Araştırmaya katılan 237 işletmeden 128'i Manisa'da, 48' i Afyonkarahisar'da, 31'i Uşak'ta, 30'u ise Kütahya'da faaliyet göstermektedir.

Tablo 2: Betimleyici İstatistikler

\begin{tabular}{|c|c|c|c|}
\hline & & Frekans & Yüzde \\
\hline \multirow{5}{*}{$\begin{array}{l}\text { İl Bazında Destekten } \\
\text { Faydalanan İşletme Sayısı }\end{array}$} & Afyonkarahisar & 368 & 17 \\
\hline & Kütahya & 303 & 14 \\
\hline & Manisa & 1.116 & 52 \\
\hline & Uşak & 371 & 17 \\
\hline & Toplam & 2.158 & 100,00 \\
\hline \multirow{5}{*}{$\begin{array}{l}\text { İ Bazında Çalışmaya Katılan } \\
\text { İşletme Sayısı }\end{array}$} & Afyonkarahisar & 48 & 20 \\
\hline & Kütahya & 30 & 13 \\
\hline & Manisa & 128 & 54 \\
\hline & Uşak & 31 & 13 \\
\hline & Toplam & 237 & 100,00 \\
\hline \multirow{5}{*}{ İşletmelerin Hukuki Statüsü } & Şahıs İşletmesi & 97 & 40,90 \\
\hline & Limited Şirket & 120 & 50,60 \\
\hline & Anonim Şirket & 15 & 6,30 \\
\hline & Adi Ortaklık & 5 & 2,10 \\
\hline & Toplam & 237 & 100,00 \\
\hline
\end{tabular}


Optimum Ekonomi ve Yönetim Bilimleri Dergisi, Cilt 4, Sayı 1- http://dergipark.ulakbim.gov.tr/usakoeyb/ Kandemir, Baykut ve Avcl- KOSGEB Desteklerinin Destekleri Kullanan İşletmeler Açısından Değerlendirilmesi (TR33 Bölgesi Uygulamasi)

\begin{tabular}{|c|c|c|c|}
\hline \multirow{6}{*}{ İşletmelerin Faaliyet Süresi } & 0-4 Yil & 101 & 41,60 \\
\hline & 5-9 Yil & 47 & 19,80 \\
\hline & 10-14 Y1l & 26 & 11,00 \\
\hline & 15-19 Y1l & 22 & 9,30 \\
\hline & $20+Y_{11}$ & 41 & 17,30 \\
\hline & Toplam & 237 & 100,00 \\
\hline \multirow{4}{*}{ İşletme Ölçekleri } & Mikro Ölçek & 105 & 44,30 \\
\hline & Küçük Ölçek & 76 & 32,10 \\
\hline & Orta Ölçek & 56 & 23,60 \\
\hline & Toplam & 237 & 100,00 \\
\hline \multirow{5}{*}{ İşletme Yöneticileri } & Sahibi & 141 & 59.50 \\
\hline & Ortaklar & 73 & 30,80 \\
\hline & Profesyonel Yönetici & 9 & 3,80 \\
\hline & Aile Üyeleri & 14 & 5,90 \\
\hline & Toplam & 237 & 100,00 \\
\hline \multirow{3}{*}{ İnternet Sitesi Sahipliği } & İnternet Sitesi Bulunan & 172 & 72,60 \\
\hline & İnternet Sitesi Bulunmayan & 65 & 27,40 \\
\hline & Toplam & 237 & 100,00 \\
\hline \multirow{3}{*}{$\begin{array}{l}\text { İnternet Üzerinden Satış } \\
\text { Durumu }\end{array}$} & İnternet Üzerinden Satış Yapan & 26 & 11,00 \\
\hline & İnternet Üzerinden Satı̧ Yapmayan & 211 & 89,00 \\
\hline & Toplam & 237 & 100,00 \\
\hline \multirow{6}{*}{ Dış Ticaret Durumu } & Dış Ticaret Yapan & 76 & 32,10 \\
\hline & Dış Ticaret Yapmayan & 161 & 67,90 \\
\hline & Toplam & 237 & 100,00 \\
\hline & Ticaret ve Sanayi Odası & 189 & 79,70 \\
\hline & Esnaf ve Sanatkârlar Odası & 38 & 16,00 \\
\hline & Ticaret Borsas1 & 4 & 1,70 \\
\hline
\end{tabular}


Optimum Journal of Economics and Management Sciences, Vo1. 4, No. 1- http://dergipark.ulakbim.gov.tr/usakoeyb/ Kandemir, Baykut and Avcl-An Assessment of Small and Medium Enterprises Development Organization (KOSGEB) Incentives from the Perspective of Support Receiving Organizations (TR33 Region Implementation)

\begin{tabular}{|l|l|l|l|}
\hline Kayıtlı Olunan Meslek Kuruluşu & Eczacılar Odası & 4 & 1,70 \\
\cline { 2 - 4 } & Mühendisler Odası & 2 & 0,80 \\
\cline { 2 - 4 } & Toplam & 237 & 100,00 \\
\hline \multirow{5}{*}{ Faaliyet Gösterilen Sektör } & Hizmet & 54 & 22,80 \\
\cline { 2 - 5 } & İmalat & 111 & 46,80 \\
\cline { 2 - 5 } & Maden & 5 & 2,10 \\
\cline { 2 - 5 } & İnşaat & 24 & 10,10 \\
\cline { 2 - 5 } & Ticaret & 33 & 13,90 \\
\cline { 2 - 5 } & Diğer & 10 & 4,20 \\
\cline { 2 - 4 } & Toplam & 237 & 100,00 \\
\hline
\end{tabular}

Tablo 2' e bakıldığında, ankete katılan 237 işletmeden 120'si limited şirket, 97'si şahıs işletmesi, 15 'i anonim şirket ve 5'i ise adi ortaklık statüsündedir. 237 işletmeden 101 'i $0-4$ yıl arasında, 47'si 5-9 yıl arasında, 26's1 10-14 yıl arasinda, 22'si 15-19 y1l arasinda, 41'i ise 20 yıldan fazla zamandır faaliyettedir. Dolayısıyla ankete katılan işletmelerin \%41,6'sı 4 yıldan az süredir faaliyetine devam etmektedir. İşletmelerin 105'i Mikro Ölçekli, 76's1 Küçük Ölçekli, 56's1 ise Orta Ölçekli işletmedir. 237 işletmeden 141'inin yöneticisi işletme sahibi, 73'ünün yöneticisi işletme ortakları, 9'unun ki profesyonel yönetici, 14'ünün ki ise aile üyeleridir. Genel olarak değerlendirildiğinde ankete katılan işletmelerin sadece $\% 3,8$ 'i profesyonel yönetici tarafindan idare edilmektedir.

Ankete katılan 237 işletmeden 24'ünün yöneticisi ilköğretim düzeyinde, 51'inin yöneticisi lise düzeyinde, 21 'inin yöneticisi meslek lisesi düzeyinde, 113'ünün yöneticisi lisans düzeyinde ve 28 'inin yöneticisi ise yüksek lisans ve üzeri düzeyde eğitim almışlardır. 237 işletmeden 172'sinin internet sitesi bulunurken 65'inin internet sitesi bulunmamaktadır. 26 işletme internet üzerinden satış yaparken, 211 işletme ise internet üzerinden satış yapmadığını belirtmiştir. 237 işletmeden 76'sı dış ticaret yaparken (ihracat veya ithalat), 161 işletmenin ise dış ticaret yapmadığı tespit edilmiştir. İşletmelerden 189'u Ticaret ve Sanayi Odası'na, 38'i Esnaf ve Sanatkârlar Odası'na, 4'ü Ticaret Borsası'na 4'ü Eczacilar Odası'na, 2'si ise Mühendisler Odası'na kayıtlıdır. 237 işletmeden 111'i İmalat, 54'ü Hizmet, 33'ü Ticaret, 24'ü İnşaat, 5'i maden ve 10'u ise diğer sektörlerde faaliyet göstermektedirler.

KOSGEB desteklerinden yararlanma düzeylerine ilişkin istatistiklere bakıldığında ise Tablo 2'den de görüleceği üzere ankete katılan 237 işletmeden 151'i Genel Destek Programı'ndan, 41'i Girişimcilik Destek Programı'ndan, 11'i KOBİ Proje Destek Programı'ndan, 9'u Diğer desteklerden (Tematik Proje, İşbirliği Güçbirliği ve Gelişen İşletmeler Piyasası KOBİ Destek Programı), 1'i Ar-Ge, İnovasyon ve Endüstriyel Uygulama Destek Programı'ndan, 24'ü ise bu destek programlarının birden fazlasından faydalanmıştır. 
Tablo 3: KOSGEB Destekleri Tanımlayıcı İstatistikler

\begin{tabular}{|c|c|c|c|}
\hline \multirow{8}{*}{$\begin{array}{l}\text { Faydalanılan KOSGEB } \\
\text { Desteği }\end{array}$} & & Frekans & Yüzde \\
\hline & Genel Destek Programı & 151 & 63,70 \\
\hline & Girişimcilik Destek Programı & 41 & 17,30 \\
\hline & Birden Fazla Destek Programı & 24 & 10,10 \\
\hline & KOBİ Proje Destek Programı & 11 & 4,60 \\
\hline & $\begin{array}{l}\text { Diğer (Tematik Proje, İşbirliği Güçbirliği ve } \\
\text { Gelişen İşletmeler Piyasası KOBİ Destek } \\
\text { Programı) }\end{array}$ & 9 & 3,80 \\
\hline & $\begin{array}{l}\text { Ar-Ge, İnovasyon ve Endüstriyel Uygulama } \\
\text { Destek Programı }\end{array}$ & 1 & 0,40 \\
\hline & Toplam & 237 & 100,00 \\
\hline \multirow{3}{*}{$\begin{array}{l}\text { Destek Süreçlerinde Yardım } \\
\text { Alma Durumu }\end{array}$} & Yardım Alan & 109 & 46,00 \\
\hline & Yardım Almayan & 128 & 54,00 \\
\hline & Toplam & 237 & 100,00 \\
\hline \multirow{7}{*}{$\begin{array}{l}\text { Destek Kullanım Sürecinde En } \\
\text { Çok Zorluk Çekilen Aşama }\end{array}$} & KOSGEB'e kayıt aşamasında & 30 & 12,70 \\
\hline & KOSGEB'e destek başvurusu aşamasında & 47 & 19,80 \\
\hline & KOSGEB'e Proje/İş Planı hazırlama aşamasında & 57 & 24,10 \\
\hline & KOSGEB destek ödemesi aşamasında & 91 & 38,40 \\
\hline & Diğer & 6 & 2,50 \\
\hline & Hiçbir Aşama & 6 & 2,50 \\
\hline & Toplam & 237 & 100,00 \\
\hline
\end{tabular}

İşletmelerin destek süreçlerinde yardım alma durumuna bakıldığında ise; 237 işletmeden 109'u destek süreçlerinde danışmanlık firmaları, muhasebeciler vb. bir başka kişiden destek aldıklarını, 128'i ise herhangi bir destek almadan bu süreçleri kendilerinin gerçekleştirdiğini ifade etmişlerdir. İşletmelere göre destek kullanım sürecinde en çok zorluk çekilen aşama 237 işletmeden 91'ine göre destek ödemesi aşaması, 57'sine göre proje/iş planı hazırlama aşaması, 47'sine göre destek başvurusu aşaması, 30'u KOSGEB'e kayıt aşamasında, 6'sı ise bunların dışında kalan diğer aşamalarda zorluk çektiğini ifade ederken, 6 işletme ise hiç bir aşamada zorluk çekmediğini ifade etmiştir.

İşletmelerin KOSGEB desteklerine ilişkin sorulara verdikleri cevaplarla oluşturulan tutum ölçeğinde tutum değerleri 1 ile 5 arasında derecelendirilmiştir. 1, ankette belirtilen değerlendirmeye 'Kesinlikle Katılmıyorum' anlamına gelirken, 5, ise 'Tamamen Katılıyorum' anlamına gelmektedir. Ölçekte diğer tutum değerleri bu iki değer arasında değişmektedir.

Tablo 4: Tutum Ölçeği İstatistikleri

\begin{tabular}{|c|c|c|c|c|c|c|c|c|}
\hline Önerme & Z & 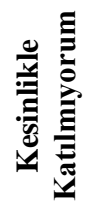 & 志 & 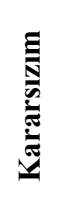 & E & 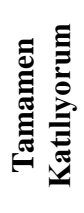 & & 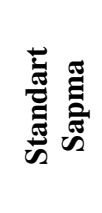 \\
\hline $\begin{array}{l}\text { KOSGEB desteklerinden nasıl } \\
\text { faydalanabileceğimi biliyorum. }\end{array}$ & 237 & 7 & 44 & 58 & 86 & 42 & 3,47 & 1,0757 \\
\hline $\begin{array}{l}\text { KOSGEB mevzuatı işletmelerin } \\
\text { rahatlıkla anlayabileceği bir } \\
\text { mevzuattır. }\end{array}$ & 237 & 7 & 49 & 84 & 76 & 21 & 3,23 & 0,9748 \\
\hline
\end{tabular}


Optimum Journal of Economics and Management Sciences, Vo1. 4, No. 1- http://dergipark.ulakbim.gov.tr/usakoeyb/ Kandemir, Baykut and Avcl-An Assessment of Small and Medium Enterprises Development Organization (KOSGEB) Incentives from the Perspective of Support Receiving Organizations (TR33 Region Implementation)

\begin{tabular}{|c|c|c|c|c|c|c|c|c|}
\hline $\begin{array}{l}\text { KOSGEB destekleri hakkında } \\
\text { bilgiye kolaylıkla ulaşabiliyorum. }\end{array}$ & 237 & 7 & 23 & 50 & 104 & 53 & 3,73 & 1,0099 \\
\hline $\begin{array}{l}\text { KOSGEB'in internet üzerindeki } \\
\text { destek başvuru sisteminin kolay ve } \\
\text { anlaşılabilir olduğunu } \\
\text { düşünüyyorum. }\end{array}$ & 237 & 7 & 27 & 76 & 95 & 32 & 3,50 & 0,9639 \\
\hline $\begin{array}{l}\text { KOSGEB desteği başvuru } \\
\text { sürecinde herhangi bir sorunla } \\
\text { karşılaşmıorum. }\end{array}$ & 237 & 12 & 39 & 71 & 85 & 30 & 3,35 & 1,0569 \\
\hline $\begin{array}{l}\text { KOSGEB destek ödeme sürecinde } \\
\text { herhangi bir sorunla } \\
\text { karşılaşmıyorum. }\end{array}$ & 237 & 37 & 49 & 63 & 64 & 24 & 2,95 & 1,229 \\
\hline $\begin{array}{l}\text { Destek süresince KOSGEB } \\
\text { personelinin yeterli ilgiyi } \\
\text { gösterdiğini düşünüyorum. }\end{array}$ & 237 & 10 & 28 & 36 & 107 & 56 & 3,72 & 1,0807 \\
\hline $\begin{array}{l}\text { KOSGEB destek oranlarının } \\
\text { yeterli olduğunu düşünüyorum. }\end{array}$ & 237 & 33 & 56 & 77 & 55 & 16 & 2,85 & 1,1309 \\
\hline $\begin{array}{l}\text { KOSGEB desteklerinin rekabet } \\
\text { gücümüzün artmasında etkisi } \\
\text { olduğunu düşünüyorum. }\end{array}$ & 237 & 15 & 32 & 44 & 104 & 42 & 3,53 & 1,1218 \\
\hline $\begin{array}{l}\text { KOSGEB desteklerinin ciromuzun } \\
\text { artmasında etkisi olduğunu } \\
\text { düşünüyorum. }\end{array}$ & 237 & 20 & 41 & 44 & 94 & 38 & 3,38 & 1,1889 \\
\hline $\begin{array}{l}\text { KOSGEB desteklerinin istihdam } \\
\text { artışında etkisi olduğunu } \\
\text { düşünüyorum. }\end{array}$ & 237 & 11 & 22 & 39 & 115 & 50 & 3,72 & 1,0448 \\
\hline $\begin{array}{l}\text { KOSGEB desteklerinin } \\
\text { ihracatımızın artmasında etkisi } \\
\text { olduğunu düşünüyorum. }\end{array}$ & 237 & 15 & 33 & 73 & 84 & 32 & 3,36 & 1,0785 \\
\hline $\begin{array}{l}\text { KOSGEB desteklerinden tekrar } \\
\text { faydalanmayı düşünüyorum. }\end{array}$ & 237 & 11 & 7 & 34 & 92 & 93 & 4,05 & 1,0362 \\
\hline
\end{tabular}

Tutum ölçeği değerlendirmesinde işletmelerin destek ve destek süreçlerine ilişkin tutum ortalamaları genellikle 3 (Kararsızım) ile 4 (Katılıyorum) arasında değişmektedir. Buradan işletmelerin destek ve destek süreçleri hakkındaki genel tutumlarının istatistikî açıdan olumlu olduğu görülmektedir. KOSGEB desteklerinden yararlanan işletmelerin özellikle “ KOSGEB desteklerinden tekrar faydalanmayı düşünüyorum.” önermesine yüksek oranda olumlu görüş bildirmesi (4,05 ortalama) KOSGEB desteklerinin işletmeler üzerindeki olumlu etkisinin göstergesidir.

Çalışmada yapılan bir diğer analiz türü ise karşılaştırmalı analizlerdir. Yapılan analizler sonucunda yanıt veren gruplar ile önermelere verilen yanıtlar arasında istatistiksel açıdan anlamlı farklılık olup olmadığ 1 tespit edilmeye çalışılmıştır. Tablo 5 'te yanıt grupları ile önermelere verilen yanıtlar arasında $\% 5$ anlamlılık düzeyinde istatistiksel olarak anlamlı farkl1lık tespit edilmiş ise "+" ile istatistiksel olarak anlamlı farklılık yok ise "_“ işareti ile gösterilmiştir.

Genel Destek Programı, KOBİ Proje Destek Programı veya Girişimcilik Destek Programı'ndan (X=Kullanılan destek programı) faydalanan ve faydalanmayan işletmelerin, 
hukuki statü, işletme ölçeği, yöneticinin eğitim durumu vb. olmak üzere toplam 15 adet yapısal kritere ( $\mathrm{Y}=$ Yapısal kriter) göre destek kullanım durumlarının istatistiksel açıdan anlamlı bir farklılık gösterip göstermediğine ilişkin toplam 45 adet hipotez oluşturularak test edilmiş ve sonuçlar Tablo 5'te verilmiştir.

Tablo 5: Karşılaştırmalı Analizler

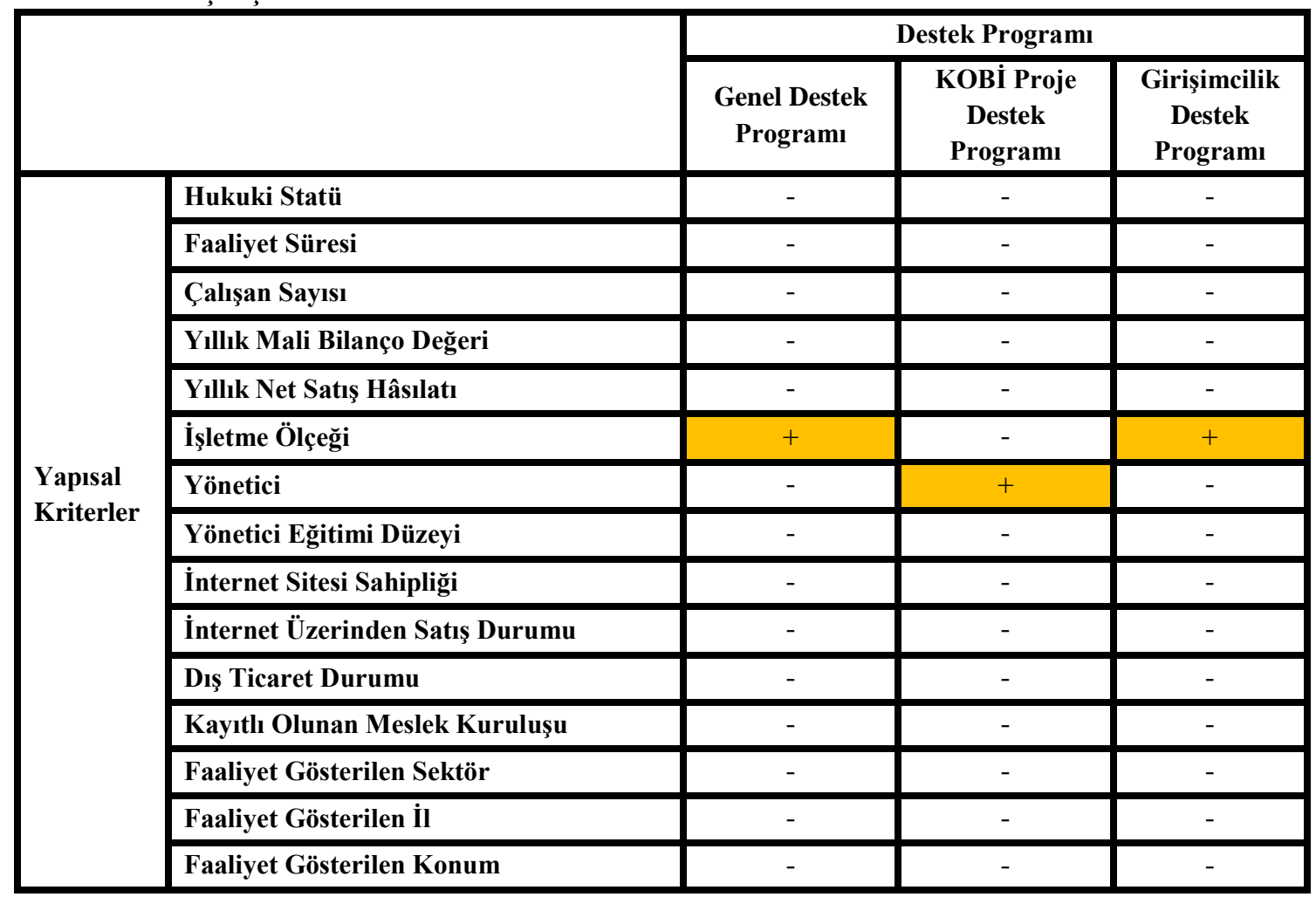

Çalışmada yapısal kriter olarak belirlenen ve yanıt grubu olarak analizlere dahil edilen 15 faktörün destek programları arasında istatistiksel olarak anlamlı farklılık yaratıp yaratmadığının tespiti için yapılan analizlerde, yanıt gruplarının sadece iki tanesinde (işletme ölçeği ve yönetici) \%5 anlamlılık düzeyinde istatistiksel olarak anlamlı farklılıklar tespit edilmiştir. Diğer 13 grup arasında ise yararlanılan destek gruplarına göre farklılaşma tespit edilememiştir. $\mathrm{Bu}$ durumu örnek verilecek olunursa; KOBİ Proje Destek Programı'ndan faydalanan işletmeler ile faydalanmayan işletmelerin kayıtlı olduğu meslek kuruluşları arasında istatistiksel açıdan anlamlı bir farklılık yoktur. Yani KOBİ Proje Destek Programı'ndan faydalanan işletmeler genellikle Ticaret ve Sanayi Odası'na kayıtlı iken faydalanmayan işletmeler Esnaf ve Sanatkârlar Odası'na kayıtlıdır benzeri çıkarımlarda bulunulamaz. Buna karşın incelemeye konu iki önermede ise istatistiksel olarak anlamlı farklılık tespit edilmiştir. Genel Destek Programı'ndan faydalanan işletmeler ile faydalanmayan işletmelerin işletme ölçeklerinde istatistiksel açıdan anlamlı bir farklılık vardır. Genel Destek Programı'ndan faydalanan işletmeler ağıllıklı olarak küçük ve orta ölçekli işletmeler iken faydalanmayan işletmeler genellikle mikro ölçekli işletmelerdir.

TÜİK 2015 verilerine göre ülkemizde bulunan işletmelerin \%99,8'i KOBİ'lerden oluşmaktadır. KOSGEB'in en kolay başvurulabilen destek programı ise Genel Destek Programıdır. Analiz sonucundan da anlaşılacağı üzere bu destekten faydalanan işletmeler ağırlıklı olarak küçük ve orta ölçekli işletmelerdir. Proje kültürü gelişmemiş olan mikro ölçekli işletmelerin büyük bir bölümünün, en çok ve en kolay şekilde faydalanılması gerektiği düşünülen Genel Destek Programı'ndan faydalanmaması bu destek programının onlara yeterince hitap etmemesindendir. KOSGEB tarafindan Genel Destek Programı kapsamında bulunan 

Incentives from the Perspective of Support Receiving Organizations (TR33 Region Implementation)

desteklerin mikro ölçekli işletmelerce daha kullanılabilir ve ulaşılabilir hale getirilmesine yönelik çalışmalar yapılabilir.

İstatistiksel olarak \%5 anlamlılık düzeyinde anlamlı farklılık tespit edilen bir diğer faktör ise işletmelerin yöneticileri ile alakalıdır. KOBİ Proje Destek Programı'ndan faydalanan işletmeler ile faydalanmayan işletmelerin yöneticileri arasında istatistiksel açıdan anlamlı bir farklılık vardır. KOBİ Proje Destek Programı'ndan faydalanan işletmeler arasında profesyonel yöneticiler tarafından idare edilen işletmelerin oranı fazla iken, faydalanmayan işletmeler ise genellikle sahipleri, ortakları veya aile üyeleri tarafından yönetilen işletmelerdir. KOBİ Proje Destek Programı'nın faydalanan işletmelerin ağırlıklı olarak profesyonel yöneticiler tarafından idare edilmesi, profesyonel yönetim anlayışına sahip işletmelerin proje kültürlerinin gelişmesinden ve kurumsallaşmadan kaynaklanmaktadır. Sahipleri, ortakları veya aile üyeleri tarafından yönetilen işletmelerde genellikle proje kültürü gelişmemiş, kurumsallaşma yolunda aşama alınmamıştır. KOBİ Proje Destek Programı'nın amacının işletmelerin proje kültürlerini geliştirmek olduğu düşünülürse, sahipleri, ortakları veya aile üyeleri tarafından yönetilen işletmelerin bu destek programının önemini daha iyi kavramaları gerekmektedir.

Girişimcilik Destek Programı'ndan faydalanan işletmeler ile faydalanmayan işletmelerin, işletme ölçeklerinde de istatistiksel açıdan anlamlı bir farklılık vardır. Girişimcilik Destek Programı'ndan faydalanan işletmeler ağıllıklı olarak mikro işletmeler iken faydalanmayan işletmeler genellikle küçük ve orta ölçekli işletmelerdir. Bu destekten faydalanan işletmeler genelde yeni kurulan işletmeler olup en fazla bir veya birkaç y1llık işletmelerdir. Bu yüzden bu destekten faydalanan işletmelerin mikro ölçekli işletmeler oluşu Girişimcilik Destek Programı'nın yapısından kaynaklanmaktadır.

Genellikle farklı destek programından faydalanan işletmelerin performans kriterlerindeki değişim değerleri arasında istatistiksel açıdan anlamlı bir farklılık yoktur. Yani destek programlarının işletme performans kriterlerini etkileme durumları arasında birbirine göre üstünlüğ̈̈ olmadığ 1 görülmektedir. Ancak Tablo 6'da görüldüğg̈ üzere KOBİ Proje Destek Programı'ndan faydalanan işletmelerin Genel Destek Programı ve Girişimcilik Destek Programı'ndan faydalanan işletmelere göre rekabet güçlerindeki değişim değerleri arasında istatistiksel açıdan anlamlı bir farklılık vardır.

Tablo 6: Destek Programları

\begin{tabular}{|l|c|c|c|}
\hline \multicolumn{1}{|c|}{ Kullanılan Destek Programı } & $\begin{array}{c}\text { Genel Destek } \\
\text { Programı }\end{array}$ & $\begin{array}{c}\text { KOBİ Proje Destek } \\
\text { Programı }\end{array}$ & $\begin{array}{c}\text { Girişimcilik Destek } \\
\text { Programı }\end{array}$ \\
\hline Genel Destek Programı & ------ & - & - \\
\hline KOBİ Proje Destek Programı & + & ------ & + \\
\hline Girişimcilik Destek Programı & - & - & ------ \\
\hline
\end{tabular}

KOBİ Proje Destek Programı'ndan faydalanan işletmeler Genel Destek Programı ve Girişimcilik Destek Programı'ndan faydalanan işletmelere göre rekabet güçlerinin daha fazla olumlu yönde değiştiğini ifade etmişlerdir. KOSGEB'in KOBİ Proje Destek Programı diğer destek programlarına göre işletmelerin rekabet gücünü arttırma konusunda öne çıkmaktadır. Bu açıdan bu desteğin işletmeler açısından daha ulaşılabilir ve kullanılabilir hale getirilmesi KOSGEB desteklerinin etkinliğinin artırılması açısından önem arz etmektedir.

\section{SONUC}

KOBI'ler gelişmiş ve gelişmekte olan ülke ekonomilerinde önemli bir role sahiptirler. KOBİ'ler bağımsız birer firma olarak ekonomiye yaptıkları katkıların dışında, ekonomi içerisinde bulunan büyük ölçekli işletmelerinde tamamlayıcıları olmaları bakımından ekonomiye çift yönlü katkı yapmaktadırlar. Ayrıca büyük ölçekli işletmelerin girmedikleri veya girmekten 
çekindikleri pazarlara girerek bu alanlardaki açıkları kapatmaktadırlar. İstihdam ettikleri işgücünden, yaptıkları yatırımlara, ödedikleri vergilerden, sağladıkları verimliğe kadar birçok konuda ekonomilerin vazgeçilmezi olan KOBİ'ler, tüm bu etkilerine karşı devlet destekleri söz konusu olduğunda geri plana itilebilmekte ve desteklerden aktif olarak faydalanamamaktadırlar.

Oysaki girişimciliğin desteklenmesi, KOBİ'lerin kurulması, büyümesi ve gelişmesi ülke ekonomileri için son derece önemli bir unsurdur. Bu hususun farkında olan gelişmiş ve gelişmekte olan ülkeler başta olmak üzere hemen hemen tüm ülkeler ekonomi politikalarını KOBI'lerin sayısının artması, hayatta kalması, gelişmesi ve rekabet avantajlarının artması üzerine kurgulamaya başlamışlardır. Ayrıca KOBİ politikalarının yerel olmaktan çıkıp küresel bir nitelik de kazanmaya başlamıştır. Bu durumun bir göstergesi olarak 2016 yılı içinde düzenlenen OECD toplantısı ve G20 toplantısında KOBİ ana başlığı açılarak KOBİ'lerin küresel olarak odaklanılan bir konu haline gelmesi amaçlanmıştır. Çünkü artık bir ülkenin küçük bir yerleşim yerinde bulunan küçük bir işletmenin rakibi sadece o yerleşim yerinde bulunan diğer işletmeler değildir. Başka bir ülkenin herhangi bir yerleşim yerinde bulunan aynı sektördeki herhangi bir işletmede artık rakip haline gelmiştir. Bu durumun farkında olan ülkeler, bir taraftan makro düzeyde iyileştirme çalışmaları yürütürken, diğer taraftan işletmelere yönelik çeşitli destek araçları geliştirerek mikro düzeyde müdahaleler yapmakta ve ülkelerindeki KOBİ'lerin uluslararası rekabette öne geçmelerini arzulamaktadır.

Destek uygulamalarında genellikle ülkelerin deneyimleri, öncelikleri, destek hacimleri ve araçları farklılıklar göstermektedir. Desteklerin başarılı ve etkin olabilmesi için her ülke, kendi gelişmişlik düzeyini, ekonomik durumunu, finans sisteminin yapısını, işletme özellikleri ve ihtiyaçları ile politika önceliklerini göz önünde bulundurarak desteklerini geliştirmektedir. Özellikle gelişmiş ülkelerde yeni girişimcilerin, yenilikçi ve hızlı büyüme potansiyeli olan işletmelerin finansmanına büyük önem verilmektedir.

Ülkemizde de son yıllarda destek programları bu çerçevede yapılandırılmakta ve yeni girişimciler ile yenilikçi KOBİ'lerin desteklenmesine yönelik programlar oluşturulmaktadır. Ülke geneline yaygın teşkilat ağı ile desteklerin tüm girişimciler ve KOBİ'ler için ulaşılabilir olmasını sağlayan KOSGEB ülkemizin KOBİ politikalarının hayat bulduğu kurumların başında gelmektedir. KOSGEB tarafından işletmelere ulaştırılan bu desteklerin işletmeler tarafından nasıl karşı1ık bulduğu, onların ekonomik hayatını nasıl etkilediği KOSGEB desteklerinin etkinliğinin ölçülmesi bakımından önem arz etmektedir. Bu kapsamda yapılan araştırma, işletmelerin KOSGEB destekleri hakkındaki genel görüşlerinin belirlenmesi ve araştırma sonucunda ortaya konulacak önerilere kaynak oluşturması bakımından önemlidir. Çalışma kapsamında incelenen TR33 Bölgesi'nde KOSGEB desteklerinden faydalanan işletmelerin KOSGEB desteklerinden memnun olma düzeylerinin ortalamanın üzerinde olduğu görülmektedir. Destekten faydalanan işletmelerin büyük kısmı desteklerin performanslarını arttırdığını ifade etmiştir. Araştırma kapsamında elde edilen veriler analiz edildiğinde KOSGEB destekleri ve destek süreçleri açısından aşağıda belirtilen hususlarda iyileştirmeler yapılması işletmeler açısından olumlu olabilecektir.

İşletmeler ağılıklı olarak projesiz destekleri kullanmaktadırlar. Bu desteklerin tercih edilmesinin sebebi destek öncesi herhangi bir hazırlık ve planlama sürecinin olamamasıdır. İşletme yöneticilerinin proje kültürleri henüz tam olarak gelişmediği için bu destekler cazip gelmektedir. KOSGEB tarafından sunulan destekler arasında proje/iş planı gerektirmediği için destek süreçleri en kolay program olan Genel Destek Programı içerisinde bulunan destekler daha çok imalatçı KOBI'ler için tasarlanmıştır. Genel Destek Programı'nda küçük esnaf ve sanatkârların aktif olarak faydalanabileceği desteklerin olmaması esnaf ve sanatkârları sadece Girişimcilik Destek Programı'na mahkûm etmektedir.

Girişimcilik Destek Programı'ndan faydalanan işletmeler eğer imalatçı değillerse daha sonra yararlanabilecekleri başka çeşitli KOSGEB destekleri bulunmamaktadır. Örnek olarak 

Incentives from the Perspective of Support Receiving Organizations (TR33 Region Implementation)

KOSGEB tarafindan desteklenen sektörler arasında bulunan bir kuaför veya marketin, Girişimcilik Destek Programı dışında faydalanabilecekleri destek çeşidi sayısı sınırlıdır. KOSGEB destekleri bu tür işletmelerin kuruluş aşamasında yanında iken daha sonraları onları acımasız rekabet koşulları karşısında yalnız bırakmaktadır. Bu tür işletmelerin beklentileri özellikle Kredi Faiz destekleridir.

KOSGEB tarafından en son 2010 yılında kullandırılan ve artık daha çok özel durumlar ve bölgeler için sunulan (deprem, sel vs.) Kredi Faiz Destek Programı destekleri küçük esnaf ve sanatkârlar için çok faydalı bir destektir. Kullandırılan destek tutarı sınırlı olmasına rağmen bankalar aracılığı ile piyasada büyük ölçüde nakit dolaşıma girmektedir. Bu destek piyasanın nakit sıkışıklığını açabilecek sihirli bir değnektir. Bu açıdan Kredi Faiz Destek Programı'nın daha aktif hale getirilmesi özellikle küçük esnaf ve sanatkârlar için çok önemlidir. Ayrıca 19902009 yılları arasında KOSGEB'in yapmış olduğu başarılı çalışmalardan dolayı 2009 yılından itibaren imalat sanayisi dışındaki tüm sektörlerdeki KOBİ’lerin rekabet avantajının arttırılması ve geliştirilmesi işlevi KOSGEB'e bırakılmıştır. KOSGEB bu göreve yönelik olarak destek programlarını revize etmiştir. Ancak destekler arasında hala imalat sanayi KOBİ'lerinin faydalanabileceği destekler ağırlıktadır. Küçük esnaf ve sanatkârların faydalanabileceği yeni programlar geliştirilerek bu tür işletmelere daha fazla destek sağlanmalıdır.

Destek kullanan işletmeler destek süreci boyunca en çok destek ödemesi aşamasında sıkıntı çektiklerini belirtmişlerdir. Hak edilmiş olan desteğin gecikmesi özellikle proje/iş planı bazlı destekler için büyük sıkıntı oluşturmaktadır. Bu durum bazen projenin/iş planının kesintiye uğramasına ve başarısızlıkla sonuçlanmasına sebep olabilmektedir. Ödeme süreçleri her ne kadar tek başına KOSGEB'in kontrolünde olmasa da KOBI'lerin ve KOBİ desteklerinin ülke ekonomisi açısından önemi dikkate alınarak bu konuda ilgili kurumlar tarafından gerekli önlemler alınmalı ve en azından kabul edilmiş proje/iş planlarının ödeme süreçlerinde gecikmeler yaşanmamalıdır. Yine yapılan çalışmada işletmelerin destek süreçlerinde en çok zorluk çektikleri aşamalar arasında proje/iş planı hazırlama aşamasının ikinci sırada olduğu görülmüştür. Zorluklarla karşılaşan işletmeler bir şekilde bu zorlukları aşamadıkları zaman ya danışmanlık şirketlerine yönelmekte ya da destek başvurusundan vazgeçmektedir. Neredeyse işletmelerin yarıya yakınının desteklere başvuru aşamasında yardım almalarının nedenlerinden biri de yine proje/iş planı hazırlama aşamasında çektikleri sıkıntılardır. Ancak proje destekleri kapsamında olan KOBİ Proje Desteği ve Ar-Ge, İnovasyon ve Endüstriyel Uygulama Desteği gibi destekler işletmelerin küresel rekabet koşullarına kendilerini hazırlayabilmeleri açısından büyük önem arz etmektedir. KOBİ'lerin büyümesi ve büyük ölçekli işletme sınıfına geçerek marka işletmeler haline gelebilmeleri için onların proje bazlı desteklere yönlendirilerek proje kültürlerini geliştirmelerini sağlamak gerekmektedir. $\mathrm{Bu}$ yüzden proje/iş planı hazırlama aşamasında işletmeleri bu destekleri kullanmaktan vazgeçiren veya başvurunun başarısız bir girişim olarak kalmasına neden olan engellerin kaldırılması, zorlukların azaltılması gerekmektedir.

Girişimcilik Destek Programı'ndan faydalanan işletmelerin yaklaşık yarısı iş planı hazırlama aşamasında danışmanlık firmalarından destek almaktadır. Hâlbuki girişimciler iş planlarını hazırlamadan ve işletmelerini kurmadan önce KOSGEB tarafından düzenlenen Uygulamalı Girişimcilik Eğitimleri 'ne katılabilirler. Bu eğitimlerde girişimcilere iş planı hazırlama konusunda da dersler verilmektedir. Buna rağmen danışmanlık firmalarından destek alan girişimci sayısının bu kadar yüksek olmasının nedeni bu eğitimlerin yeterince başarılı olmadığını ortaya koymaktadır. Bunun durum ya bazı eğitmenlerin yetersiz olmasından ya da eğitimlerin içeriğinin girişimcilerin anlayabileceği düzeyde olmamasından kaynaklanmaktadır. Uygulamalı Girişimcilik Eğitimlerinin etkinliğinin arttırılması girişimcileri danışmanlık firmalarına mahkûm olmaktan kurtaracaktır. 
İşletmelerin büyük kısmı, KOSGEB'in çevrimiçi başvuru sisteminin ve destekler hakkında bilgiye ulaşma yollarının kolay ve anlaşılabilir olduğunu düşünmektedirler. Bununla beraber sistemin geliştirilerek bütün işletmelerin kolaylıkla başvurularını yapabilmesi amaçlanmalıdır. Yine işletmelerin önemli bir kısmı KOSGEB desteklerinin rekabet güçlerini ve istihdam sayılarını arttırdığını ifade etmişlerdir. Buradan KOSGEB'in KOBİ'lerin rekabet güçlerini arttırma hedefi ile oluşturduğu destek programlarının bu amaç doğrultusunda işlev gördügü anlaşılmaktadır.

İşletmelerin en çok memnun olduğu konulardan birisi de KOSGEB personelinin destek süreçlerinde kendilerine gösterdiği ilgi olmuştur. Çalışma sonuçlarına göre işletmelerin büyük kısmı KOSGEB personelinin destek süreçlerinde kendilerine gösterdiği ilgiden memnun kaldıklarını belirtmiştir. Bu durum KOSGEB'in personel seçim ve yetiştirme politikasının başarılı olduğunu göstermektedir. Benzer şekilde işletmelere göre desteklerin devam etmesini istemekle beraber destek oranlarının arttırılması gerektiğini düşünmektedirler. İşletme beklentilerine yönelik olarak, bütçe imkânları dâhilinde destek oranlarının yukarı yönlü revizesi tartışılabilir.

Bu çalışmanın amacı TR33 Bölgesinde KOSGEB desteklerinden faydalanan işletmelerin destekler hakkındaki düşüncelerini ve beklentilerini öğrenmekti. Çalışma sonuçlarına göre genel olarak TR33 Bölgesinde destek alan işletmelerin desteklerden ve KOSGEB'ten memnuniyet düzeyinin istatistikî olarak ortalamanın üzerinde olduğu görülmektedir. Bununla beraber sonuç kısmında belirtilen konularda gerekli düzenlemeler yapılarak işletmelerin memnuniyet düzeyleri daha da arttırılabilir.

Yapılan literatür araştırmasına ve çalışma kapsamında incelenen TÜİK ve KOSGEB verilerine göre TR33 Bölgesinin ekonomik göstergelerinin, Türkiye'nin ekonomik göstergeleri ile benzer özellikler taşıdığı görülmektedir. Bu açıdan çalışma TR33 Bölgesinde KOSGEB desteklerinden faydalanan işletmeler üzerinde yapılamasına rağmen, diğer bölgelerdeki desteklerden faydalanan işletmelerin ve henüz destek kullanmayan işletmelerin de benzer görüş ve öneriler de bulunabileceği varsayılabilir. Tüm bu işletmelerin sorunları, gereksinimleri, bilgi düzeyleri aynı noktalara dikkat çekmektedir. Bu durum yapılan çalışmanın ülke geneli için bir bakış açısı oluşturabilmesi açısından önemlidir.

\section{KAYNAKÇA}

Akyüz, Y. (2013), Üniversite Öğrencilerinin KOSGEB Desteklerine Bakış Açıları Ve Girişimcilik Eğilimleri Üzerine Bir Araştırma: Uşak Üniversitesi Örneği, Uşak Üniversitesi Sosyal Bilimler Dergisi, 2013, 6/3.

Aycı, A. (2011), Pazarlama Karması Açısından Yurtdışı Fuarlar: KOSGEB Yurtdışı Desteklerinden Faydalanan KOBİ'lere Yönelik Bir Araştırma. Gazi Üniversitesi İktisadi ve İdari Bilimler Fakültesi Dergisi, $13 / 3$ (2011). 159182.

Cansız, M., (2008), Türkiye de KOBILLER ve KOSGEB, Devlet Planlama Teşkilatı Uzmanlık Tezi, Ankara, Türkiye.

Durman, M., Önder, H. (2007), Ekonominin Minik Devi KOBİ'ler ve KOSGEB Teşvikleri, Alfa Aktüel Yayıncılık, İstanbul, Türkiye, 3 .

Erol, M. (2010), Ekonomik Kriz ve KOBİ'ler, Çanakkale Onsekiz Mart Üniversitesi Girişimcilik ve Kalkınma Dergisi, 5,123 .

Ar, M. (2009), KOBİlere Verilen Teşvik ve Destekler Kapsamında KOSGEB Konya Örneği, Karamanoğlu Mehmetbey Üniversitesi_Sosyal Bilimler Enstitüsü, YL Tezi.

Mutlu, S. (2014), KOSGEB'in Uygulamalı Girişimcilik Sertifikası Eğitimi Kurslarına Katılan Kursiyerlerin Girişimcilik Potansiyelleri ve Eğilimleri, Girişimcilik ve Kalkınma Dergisi, Cilt. 9, Sayı 1 Yaz 2014.

ILO, (2005) World Employment Report, 2004-2005, Cenevre, İsviçre.

Iraz, R. (2005), Girişimcilik ve KOBİler Yaratıcılı ve Yenilik Bağlamında, Çizgi Kitabevi Yayınları, Konya, Türkiye, 230-231, 239-240. 

Incentives from the Perspective of Support Receiving Organizations (TR33 Region Implementation)

KOSGEB, (2011), KOBİ Stratejisi ve Eylem Planı 2011-2013, Ankara, Türkiye.

KOSGEB, [Çevrim-içi: http://www.kosgeb.gov.tr/site/tr/genel/detay/1230/genel-destek-programi], Erişim tarihi: 01.08.2016.

Maden, S. I. ve Dulupçu, M. A. (2014), KOBİ'lere Desteklemek Firmaların Performansını Ne Kadar Etkiler? Göller Bölgesinde KOSGEB Genel Destek Programından Yararlanan Firmalar Üzerine Bir İnceleme, Süleyman Demirel Üniversitesi İktisadi ve İdari Bilimler Fakültesi Dergisi, Y.2014, C.19, S.2, s.179-195.

OECD, (2002), Small and Medium Enterprise Outlook, Paris, Fransa.

Olcay. F.M., (1996), Gümrük Birliği Sürecinde Mali Yardımların Küçük ve Orta Boy Işsletmelere (KOBİ) Etkisi, Vakıfbank Yayınları, Ankara, Türkiye, 3.

Öktem, M. K., Aydın, M. D. ve Ekinci, S. (2007), Türkiye'de Girişimciliğin Geliştirilmesinde KOSGEB'in Rolü ve Önemi: Uygulamalı Bir Çalışma, Sosyoekonomi, 2007/1.

Özdemir, S., Ersöz, H.Y., Sarığlu, H.İ., (2006), İşsizlik Sorununun Çözümünde KOBİlerin Desteklenmesi, İstanbul Ticaret Odası Yayınları, İstanbul, Türkiye, 2006-45, 44.

Sarıkahya, M. (2012), Mobilya Endüstrisinde KOBİ'lere Verilen Devlet Desteklerinin Firmalar Üzerindeki Etkileri (Ankara Örneği). Politeknik Dergisi, Cilt:15 Sayı: 4 s. 177-183, 2012.

Valandova, S., (2003), Türkiye de KOBİlere Yönelik Destek Programlarının Yeniden Yapılandırlması, Devlet Planlama Teşkilatı Yayınlanmamış Uzmanlık Tezi, Ankara, Türkiye.

Yıldız, S. B. (2013), KOBİ’lere Sağlanan Kamu Desteklerinde Etki Değerlendirmesinin Önemi, CBÜ Sosyal Bilimler Dergisi, Cilt:11, Sayı:2, Ağustos 2013. 